\begin{tabular}{|l|l|l||}
\hline \multicolumn{2}{|c|}{ PublisherInfo } \\
\hline \hline PublisherName & $:$ & BioMed Central \\
\hline \hline PublisherLocation & $:$ & London \\
\hline \hline PublisherImprintName & $:$ & BioMed Central \\
\hline \hline
\end{tabular}

\title{
Functional heterogeneity of osteoclasts
}

\begin{tabular}{|l|l|l||}
\hline \multicolumn{2}{|c|}{ ArticleInfo } \\
\hline \hline ArticleID & $:$ & 2 \\
\hline \hline ArticleDOI & $:$ & $10.1186 /$ ar-1999-66735 \\
\hline \hline ArticleCitationID & $:$ & 66735 \\
\hline \hline ArticleSequenceNumber & $:$ & 2 \\
\hline \hline ArticleCategory & $:$ & Paper Report \\
\hline \hline ArticleFirstPage & $:$ & 1 \\
\hline \hline ArticleLastPage & $:$ & 3 \\
\hline \hline & & RegistrationDate : 1999-10-12 \\
\hline ArticleHistory & $:$ & OnlineDate $\quad$ 1999-10-12 \\
\hline \hline ArticleCopyright & $:$ & Current Science Ltd1999 \\
\hline \hline ArticleGrants & $:$ & \\
\hline \hline ArticleContext & $:$ & 1307511 \\
\hline \hline
\end{tabular}




\section{Keywords}

Bone resorption, cathepsin, cysteine proteinase, matrix metalloproteinase, osteoclast

\section{Context}

Osteoclasts, the multinucleated cells responsible for the degradation of mineralized matrices, are thought to resorb bone by a common mechanism, despite differences in bone matrix composition. However, certain bone diseases, in which defects in resorption occur at specific sites, such as craniometaphyseal dysplasia, raise the possibility that the mechanism of osteoclastic resorption may itself be site-specific. Cysteine proteinases (CPs), particularly cathepsin K, are essential for bone resorption, whereas matrix metalloproteinases (MMPs) are involved in resorption in calvarial tissue explants, but not in resorption by isolated osteoclasts. Since the latter usually involves the use of osteoclasts isolated from long bones, it is possible that resorption by osteoclasts from different sites may utilize different proteinases. To investigate whether osteoclasts from calvarial and long bones differ in their resorptive mechanism and, if so, whether these differences are related to the substratum that they resorb.

\section{Significant findings}

Undigested, demineralized bone matrix was present in resorption zones of both long bone and calvarial explants incubated with the CP inhibitor E64. The MMP inhibitor CT1166 had a similar effect in calvarial explants, but was without effect in long bones. Activity of cathepsins B and K was identified in isolated osteoclasts and in sections of long bones, and to a lesser extent in calvarial sections. In extracts prepared from both long bones and calvariae, cathepsin B activity was found to be 10-fold higher than cathepsin K activity, but there was no difference in MMP activity between the two tissues, and both were shown to contain gelatinolytic activity. Osteoclasts isolated from both sites resorbed both cortical and calvarial bone. E64 inhibited resorption and reduced the number of pits formed by both calvarial and long bone osteoclasts, whereas CT116 was effective against only calvarial osteoclasts. Finally, the mutant mouse expressing collagenase-resistant type I collagen had a calvarial thickness four times that of its normal littermate, but no difference in dimensions of the long bones.

\section{Comments}


This paper presents the first direct evidence of differences in proteolytic enzymes used by osteoclasts from calvariae or long bones and suggests that bone resorption at these two sites occurs by distinct mechanisms. This helps to reconcile some of the conflicting reports regarding the role of MMPs in osteoclastic bone resorption. Moreover, this may provide clues to the aetiology of certain bone diseases such as craniometaphyseal dysplasia. Why there should be different mechanisms of resorption is unclear, since it was demonstrated that osteoclasts from long bones are capable of resorbing calvarial bone, even in the presence of the MMP inhibitor. The possibility that different precursors could exist for each sub population of osteoclasts is intriguing and emphasizes how little is known about osteoclast progenitors and their recruitment to bone. Clearly, this is an area that merits further investigation.

\section{Methods}

The role of CPs and MMPs in resorption was studied first by using specific inhibitors of these enzymes (E64 and CT1166 respectively) in calvarial and metacarpal sections of bone from 5-day-old Swiss random mice and assessing the area of demineralized bone matrix. Activity of cathepsins B and K was assessed both in sections of calvarial, metacarpal or metatarsal bones and in osteoclasts isolated from 5-day-old Chinchilla rabbits, by using specific peptide substrates for these proteinases coupled to methoxynaphtylamide, the liberation of which was visualized by the addition of fast blue BB or nitrosalicylaldehyde. MMP activity in tissue samples was determined using the specific fluorogenic substrate TNO211. These substrates were also used to quantify proteinase activity in tissue extracts. In addition, MMP activity in these extracts was determined by gelatin zymography. Analysis of resorption pits by light and electron microscopy was used to determine the effect of E64 and CT1166 on the resorptive activity of isolated osteoclasts seeded on to bovine cortical or calvarial bone. Calvariae and long bones from mice with a mutation in type I collagen that renders it resistant to MMP-1 were examined by light microscopy and compared with the bones from normal littermates.

\section{References}

1. Everts V, Korper W, Jansen DC, Steinfort J, Lammerse I, Heera S, Docherty AJ, Beertsen W: Functional heterogeneity of osteoclasts: matrix metalloproteinases participate in osteoclastic resorption of calvarial bone but not in resorption of long bone. FASEB J. 1999, 13: 1219-1230. 